\title{
Assumption of Risk
}

\section{and Consent Doctrine in Sport}

Authors' contribution:

A) conception and design of the study

B) acquisition of data

C) analysis and interpretation of data

D) manuscript preparation

E) obtaining funding

\author{
Azadeh Mohamadinejad ${ }^{1}$ C , Hamidreza Mirsafian ${ }^{1,2}$ B , \\ Andras Nemes $^{1 \mathrm{D}}$, Mohammad Soltanhoseini ${ }^{2}$ A \\ ${ }^{1}$ Semmelweis University, Budapest, Hungary \\ ${ }^{2}$ University of Isfahan, Iran
}

ABSTRACT

Everybody who illegally harms another not only must recover the injured person, but also, may be committed a crime and be punished. According to this doctrine, every time that a participant in a sport activity touches a fellow player, or consciously runs the risk that an opponent may be touched during the game, an offence is committed and he or she is liable. This is clearly an unacceptable situation. If this were the usual way a participant in violence was dealt with by the courts, nobody would play sport, as the risk of conviction would be too great. Sport would be unable to continue in the form that we presently know it. On the other hand, sports often have inherent risks that cannot be eliminated without destroying the very essence of the activity. Consent and assumption of risk defenses in sport accident cases significantly affect resolving the conflict between performing sport as a useful and beneficial activity versus a dangerous practice, and prevent liability from being imposed for just participation in sport activity. Thus, discussion about these defenses can help athletes be more aware of their rights.

KEYWORDS defense, inherent risk, liability, damage, athlete

\section{Introduction}

One of the challenges of tort of law is that the damaging actions cannot be banned due to social necessity. And the law of tort could not eliminate the source of losses instead of redress. Therefore, it is forced to accept some of those damaging actions. For justification of those actions it is argued that a damaged person could not claim his or her losses because his or her participation in that action is with personal consent and he accepted all dangers of that action. However, this issue is not accepted in all situations because, if the consent of damaged person could eliminate the liability of person who causes that damage, other actions such as a duel, would be accepted due to the consent of the damaged or dead person (Aghainia 2009).

Sports and physical activities are also one of the necessities of communities. Despite the varied dangers, sports due to their many benefits can't be denied people. Therefore, dangerous sports such as boxing, wrestling, karate, etc., are accepted under the law. In this issue also the principle of consent relates to damaged person (athlete, spectator, etc.); accepting the danger is the important matter for supporting the athlete who cause damage (Hess 2002). It is a defense that releases from liability injurious uses in sport. But consent in a sporting situation is very different from a non-sporting situation. Therefore study about consent and assumption of risk, its extent, and scope in the context of sport is necessary. 


\section{Consent}

Consent is a voluntary yielding to an invasion of one's interests by another. It is an act of reason, accompanied by deliberation that is made by an individual possessing sufficient mental capacity to make an intelligent choice (Wong 2010).

Consent provides a defense to the offences most commonly found in sport; for example, common assault, battery, and assault occasioning actual bodily harm (Beloff et al. 1999). When consent is raised as a defense to an action based on an intentional tort, the defendant is claiming that the plaintiff consented to the very conduct that forms the basis of the claim (Klar 1996) thus is barred from any recovery (Wong 2010).

Consent can be expressed or implied by conduct (Linden 2001), or by the circumstances surrounding the situation (Wong 2010). In other word, implied consent can be given by "entering into situations where it is generally understood that one has waived one's right to remain free from bodily contact", (Linden 2001), such as participating in contact sports like hockey or football. To be effective, consent must be given without fraud, duress, misrepresentation, coercion, undue influence, or anything akin to that. If any of the vitiating elements is present in consent, it is not consent in the eye of law (Saathi 2008, Wong 2010).

\section{Assumption of risk}

Assumption of risk is a doctrine often applied to negligent actions (Spengler \& Connaughton 2003, Citron \& Ableman 2003). This doctrine came into use in the late 19th century and early $20^{\text {th }}$ century (Hess 2002); it was based on knowledge, comprehension, and appreciation of risk (Healey 2005); and imposed as a matter of law, not the result of the investigation of facts (Wong 2010). This legal doctrine holds that sports participants assume the risks of their sport, and those who have voluntarily accepted the known and appreciated risks associated with participation in the activity are barred from recovery for injuries resulting from an activity when injured while participating in the recreational activity (Bernardi 2009, Spengler \& Connaughton 2003). Assumption of risk was described by the maxim "volenti non fit injuria", interpreted as the belief that no wrong is due to one who is willing (Prosser \& Wade 1971).

In fact, according to this doctrine, by freely assuming a known risk a plaintiff effectively negates any duty on the part of the defendant to safeguard him or her from the risk and by this approach refute the defendant's negligence (Trupia 2010).

The rationale behind the doctrine is one of public policy: by removing the threat of lawsuits arising from incidents involving only ordinary negligence and by barring suits for injuries received from inherent risks of the sport, the policy seeks to enable "vigorous and active participation in athletic activities" (Bernardi 2009, Spengler \& Connaughton 2003); as imposing the duty of care upon participants of sport and recreation would deter people from vigorous participation in such activities. It is believed that athletes will feel free to participate vigorously in their sport without fear of being sued if somebody is injured (Bernardi 2009).

Defense assumption of risk apply in the following situations:

1. The plaintiff, in advance, has given express consent to relieve the defendant of any obligation to exercise care for the plaintiff's protection and has agreed to take the chance of injury from a known risk arising from what the defendant is to do or leave undone. The defendant, who otherwise would have a duty to exercise such care, is relieved of that duty, as without a duty owed by the defendant, there can be no negligence on his part (Keeton 1977).

2. The plaintiff voluntarily entered into some relationship with the defendant with knowledge that the defendant will not provide protection against one or more future risks that may arise from the relationship (Woska 1991). In this situation, the plaintiff has consented in advance to tacitly or implicitly consenting to the defendant's negligence and relieved the defendant of an obligation of conduct toward him or her as a spectator at a baseball game who may be regarded as consenting to the risk of being hit by a ball (Drago 2002). 
3. A third situation where "assumption of risk" is applicable refers to the situation where the plaintiff, faced with a dangerous condition created by the negligence of the defendant, continues voluntarily to encounter the dangerous condition (Woska 1991, Drago 2002).

Generally, the defense of assumption of risk can be used when a plaintiff (professional or amateur) voluntarily engages in an athletic or recreational activity involving open and obvious risks (Drago 2002); and relieved the defendant of an obligation and had consented to the breach of the duty of care alleged (Beloff 1999).

Where a defendant can establish this they are absolved from liability (Schot 2005).

To use this defense, the defendant must show that the plaintiff knew of the risk and voluntarily chose to assume it. This consent effectively relieves a defendant's obligation to a certain standard of conduct toward the plaintiff. There is no longer any legal duty existing between the two. When there is no duty, there is no negligence (Wong 2010). Previously, it was insufficient to prove that the plaintiff ought to have known of the risk, or that they merely perceived the existence of danger. Rather, what needed to be established was that the plaintiff was "fully aware of the risks, fully comprehending their nature and extent, and that they voluntarily accepted the whole risk". However, the standard of knowledge required until a person will be deemed to be aware of the type or kind of an obvious risk has been slightly minimized, even if the person is not aware of the precise nature, extent, or manner of occurrence of the risk. For obvious risks, the plaintiff will have consented, despite lack of full appreciation as previously required (Schot 2005). It is not necessary for the application of assumption of risk that the injured plaintiff has foreseen the exact manner in which his or her injury occurred, so long as he or she is aware of the potential for injury by the mechanism from which the injury results (State 1997, Hess 2002, Mandell \& Dozis 2010).

The assumption of risk doctrine is used in a wide variety of situations, from the obvious to the more unusual (Mandell \& Dozis 2010). Equally unusual is the case of Hochhauser (2009), where a high school wrestler brought suit alleging that he contracted Herpes Simplex I while participating in a wrestling match. The Second Department credited the proffered expert opinions that the possibility of contracting herpes and other communicable diseases is a known problem associated with wrestling and noted the plaintiff's admission that he was aware that skin diseases could be transmitted while wrestling. The court found that by its nature, wrestling involves close contact between participants and therefore, the contraction of a communicable disease while wrestling is a risk inherent in and arising out of the sport; the plaintiff assumed that risk. His complaint was dismissed (Mandell \& Dozis 2010).

However, the doctrine of primary assumption of risk will not protect the defendant in every case where the plaintiff is engaged in a sporting or recreational activity. The general rule in athletics is that participants accept the normal and reasonable risks of activities and the ordinary blows and collisions incidental to play in which they participate (Wong 2010, Citron \& Ableman 2003, Fast 2004). The assumption of risk doctrine therefore doesn't include abnormal incidents and unreasonable manner (Citron \& Ableman 2003, Wong 2010, Bernardi 2009), and accidents which are caused inadequate supervision or where the defendant negligently concealed or increased the risks inherent in the activity (Mandell \& Dozis 2010). Overall injury due negligence, recklessness, risks which the participant is unaware of, (Wong 2010), undue violence (Healey 2005), actions that are deliberately and unnecessarily harmful (Fast 2004, Citron \& Ableman 2003); or where the athlete was under any compulsion to participate are not covered by this doctrine (Schot 2005).

As noted above, for implementation of doctrine of assumption of risk, the defendant must show that the plaintiff knew of the risk and voluntarily chose to assume it. There are some ways which defendant can show plaintiff the awareness of risk. For instance, warnings posted at sports grounds, sports halls, and swimming pools give notice of the known risks involved in sport to potential spectators and participants. If there is a warning sign clearly warning participants of potential danger, and participants ignore the sign and proceed to observe or participate after being warned and get hurt anyway, they will be deemed to have 
consented to the risks. The defendants will have the defense of assumption of risk (Jacobs 2010, Schot 2005).

Therefore, where a risk is obvious to a person exercising reasonable care for his or her own safety, the notion that an occupier must warn the entrant about the risk is neither reasonable nor just (Schot 2005). These should be obvious and direct, specific to the risk, comprehensible, and at the point of hazard (Healey 2005).

It is axiomatic that for the defense to be successful, the plaintiff must be engaged in the athletic or recreational activity at the time of the injury, and remoteness will be fatal to the defense.

Assumption of risk as a defense is not limited to plaintiffs who are true participants, but can also be applied to bystanders, spectators, and officials. This means that players, coaches, managers, referees, and others who, in one way or another voluntarily participate, must accept the risks to which their roles expose them. Moreover, its application as a defense is not solely limited to contact sports or to adults.

The assumption of risk defense has been classified as several different types or categories to assist the courts in applying the defense under various circumstances (Spengler \& Connaughton 2003). There are two types of assumption of risk. The first is an express assumption of risk, the second is implied assumption of risk (Wong 2010).

The same elements apply to both: a) the plaintiff understood the existence and nature of the specific risk, and b) the plaintiff voluntarily encountered the risk (Johnson \& Easter 2007).

\section{Express assumption of risk}

Express assumption of risk is the defense that is used when a potential plaintiff has expressly agreed before entering into the activity to assume the risks involved in the activity. Under this category, the plaintiff expressly contracts that the defendant owes no duty of care toward and to take his or her chances from a known risk (Wong 2010). This contract negates the first element of the negligence cause of action. Where there is no duty owed, there can be no negligence (Spengler \& Connaughton 2003). Therefore, if the defendant's negligence causes injury to plaintiff, the assumption of risk doctrine as a complete defense bars the plaintiff from any recovery (Wong 2010, Hess 2002). This kind of assumption of risk doctrine requires an express agreement (Johnson \& Easter 2007). Often, where express assumption of risk is at issue, there is a written document involved. Assumption of risk language will often be incorporated either into a waiver or into an agreement to participate. Where a waiver is used, principles of contract law will determine the outcome of the issue (Cotten \& Cotton 2002). However, an agreement to participate is not a contract but instead is used solely to inform participants of the nature of the activity, the risks in the activity, and their expected behavior. It is merely an affirmation by the participant that they knew of the inherent risks in the activity and chose to engage in the activity despite those risks. The result is that a well-drafted agreement to participate might amount to an express assumption of (inherent) risks, thereby relieving the defendant of liability for injuries incurred by a plaintiff (Spengler \& Connaughton 2003). While such releases are often enforceable, the law frowns upon releases intended to exculpate a party from the consequences of his own negligence, and therefore subjects them to close scrutiny (Drago 2002).

However, for a release to insulate a party from liability for his own negligent acts, the parties must express their intent in clear, unambiguous, and unequivocal language. Although the term negligence need not be used, words conveying a similar import must appear in the writing. Also it must be plainly and precisely apparent that the limitation of liability extends to negligence or other fault of the party attempting to shed his ordinary responsibility. Moreover, a release will not exculpate a defendant from intentional, grossly negligent, reckless, willful, or wanton tortuous conduct (Drago 2002). 


\section{Implied assumption of risk}

Implied assumption of risk arises when a plaintiff's reasonable conduct in encountering a known risk creates an inference that he or she has agreed to relieve the defendant's duty of care (Wong 2010). In fact, the plaintiff is aware of somebody else's negligence and fully understands a risk of harm to himself or herself by their conduct, but chooses to take part in an activity anyway (Wong 2010, Hess 2002). And by this approach manifests his willingness to accept it, and thus is not entitled to recover for harm within that risk (Hess 2002). This kind of assumption of risk requires no express agreement and is found from the particular circumstances of the case.

Implied assumptions of the risk doctrine divided in 2 categories: unreasonable or primary and reasonable or secondary (Johnson \& Easter 2007, Drago 2002).

Under implied unreasonable or secondary assumption of the risk, it is said that the plaintiff assumed the risk of the defendant's negligence, but the plaintiff's conduct in confronting a known risk was unreasonable, because the danger is disproportionate to the advantage the plaintiff is pursuing. If this occurs, the plaintiff's conduct is a type of contributory negligence, an act or omission by the plaintiff that constitutes a deficiency in ordinary care, which concurs with the defendant's negligence to comprise the direct or proximate cause of injury. In such cases, the defenses of assumption of risk and contributory negligence overlap. Then it is possible, upon submittal to a jury for consideration, that the plaintiff would be barred from recovery in the suit or limited to the amount of recoverable damages (Drago 1995).

However, reasonable assumption of the risk means that the plaintiff's decision to encounter the known risk is reasonable. In other words, the plaintiff had assumed a risk, but was acting reasonably at the time (Johnson \& Easter 2007). In this kind of implied assumption of risk, the court is faced with a dilemma: should this type of assumption of risk: a) completely bar recovery, b) be evaluated under comparative fault principles, or c) be abolished as a defense?

Courts are split on the issue. There is authority in favor of retaining this type of assumption of risk as a complete defense. Nevertheless, some courts have concluded that a plaintiff's assumption of risk, irrespective of reasonableness, should be factored into the comparative fault computation. Still other courts have held that this type of assumption of risk is not a defense at all. Reasons advanced for this extreme position include: 1 . It would be anomalous to deny recovery to a plaintiff who acted reasonably while permitting partial recovery to a plaintiff who acted unreasonably; and 2. This type of assumption of risk inequitably punishes reasonable conduct (Drago 2002).

\section{Scope the implied consent}

The defense of consent and assumption of risk presents a special problem in the realm of sports in general and for athletic participants in particular. Even if it has been accepted that the athlete, by participating in a sport activity, assumed the risks of injury, and consents to those commonly appreciated risks which are inherent in and arise out of the nature of the sport generally and flow from such participation (Wong 2010, Mandell \& Dozis 2010) it should be mentioned that if only by engaging in sport that recovery is barred, nobody could ever be held liable for their own negligence (Bernardi 2009); and sporting performance is transformed into a criminal activity (Healey 2005). The question therefore remaining is to what specific acts the players have given their consent? How should the extent or scope of the implied consent given be determined? Can it be assumed that an injured player consented to excessive violence when some participants become rougher than may be reasonably necessary?

The type of injury where a player hits another out of frustration or anger must be contrasted with the type of injury caused by forceful play. The first type is no different from an injury occurring anywhere else, and will be treated as such by the courts. The second type creates more difficulty, because the question of whether there was consent to the behavior must be considered (Healey 2005). 
Though the prevailing view appears to be that "participation in sports is taken to involve consent to the ordinary blows and collisions incidental to play, including contact that is in breach of game rules, there however exists another line of authority, primarily which stands for the proposition that participation in a contact sport evidences a willingness to submit to all bodily contacts not prohibited by the safety rules of the particular sport. Even if defendant breaches his or her duty, plaintiff can't claim compensation. Because of he assumed and accepted risk. This theory is referred to as the "rules of the game" approach. According to this theory, participating in a game does not manifest consent to contact that is prohibited by rules (Uberstine 1997).

The "part of the game" approach was also another theory. According to this theory, players regularly employ contact that is beyond that which is permitted by the rules and that because of the rough nature of the sport, players wear protective equipment such as pads and helmets. In other words, an athlete consents to all conduct that can be considered "part of the game", including contact which may violate its rules Therefore, even if the defendant breached a duty which he owed to the plaintiff, there can be no recovery because of assumption of the risk. In this theory, therefore, the factors that a court may consider relevant in deciding whether or not specific conduct fall within the scope of "part of the game" (Citron \& Ableman 2003). In spite of this, some believe neither volenti or assumption of risk nor the inherent risk doctrine apply in the criminal context and hold that "though a man may by his consent debar himself from his rights to maintain a civil action, he cannot thereby defeat proceedings instituted by the crown in the interests of the public. It would be contrary to public policy for participants to be viewed as giving consent to grievous bodily harm (Schot 2005). The rationale for the encroachment of criminal justice into the sporting world is that no segment of society can act criminally without impunity (Clarke 2000).

Some believe that athletes only consent to inherent risk, and that a court is unlikely to imply consent to risks that go beyond those inherent to the sport. Rarely is a defendant found to have acted in breach of his duty of care, but instead is absolved of liability due to the consent of the plaintiff (Beloff et al. 1999).

Until 1975, when comparative fault doctrine passed into law, some believed that assumption of risk doctrine was not an independent doctrine and a complete bar for recovery, an exception expressing assumption of risk, which is useful as a complete defense. They believed that implied assumption of risk is just an element for determining the portion of fault of the defendant in the existence of injury (Hess 2002).

In fact, analysis of the concepts of assumption of risk and consent should be case-by-case and should take into account such factors as the specific game involved, the nature of the sport, the ages and physical attributes of the participants, their respective skills and knowledge of the sport's rules and customs, their status as amateurs or professionals, the presence or absence of protective equipment, the degree of "zest" with which the game is played, the intent of the parties, the mode and conditions of the particular encounter, etc. (Citron \& Ableman 2003).

Accordingly, participants in contact sports assume greater risks of injury than participants in noncontact sports, and a professional athlete is more aware of the dangers of the activity, and presumably more willing to accept them in exchange for a salary, than is an amateur (Citron \& Ableman 2003, Beloff et al. 1999, Healey 2005, Drago 2002).

Ultimately, whether or not certain conduct falls within the scope of consent or assumption of risk will depend on the particular facts of each case (Citron \& Ableman 2003). Therefore, consent has its limits; actions outside the scope of a participant's consent could result in a civil or criminal prosecution.

\section{What is an inherent risk}

It would be a reasonable, acceptable, and often unavoidable risk that one would expect to encounter in a particular sport. For instance, getting tackled is an inherent risk of playing football, while colliding with another cyclist is an inherent risk of bicycle racing. Getting tackled would not be an inherent risk of bicycle racing, nor would colliding with a cyclist be an inherent risk of football (Bernardi 2009). 
Sports often have inherent risks that cannot be eliminated without destroying the very essence of the activity and it is accepted as a matter of law that an athlete who voluntarily participates in a sporting or recreational activity is owed no duty of care with respect to the obvious risks associated with the activity (Drago 2002). Therefore, if the athlete cannot claim damages or compensation, he or she is barred from any recovery for the harm. In other words, a defendant owes no duty to protect people from well-known, obvious, or inherent risks in an activity. Viewed from this "no duty" perspective, the inherent risk doctrine like assumption of risk doctrine may act as a complete defense by negating the defendant's duty of care. But, the doctrines of inherent risk and volenti, assumption of risk, are different. Volenti requires that the plaintiff actually knew of the risk, and that this was an unaccepted, non-inherent one, and consented to it. The voluntary assumption of risk defense operates to defeat the plaintiff's claim after breach of duty is shown. It is a defense of consent applicable to negligence actions to rely on it, the defendant must show that the plaintiff agreed to give up any cause of action and willingly ran a risk that was fully understood (Fast 2004). The defense of voluntary assumption of risk has been limited to cases where the court finds the existence of an agreement, express or implied, to exempt the defendant from liability (Linden 2001, Fast 2004). But inherent risk is an argument by the defendant that the risk was of common knowledge and that the plaintiff be imputed with this knowledge, thus reducing or eliminating the standard of care owed (Yeo 2001).

In fact, the plaintiff knew of the risk of injury arising from participating in a sport activity and voluntarily assumed it by agreeing to participate (Wong 2002). Therefore, where injury arises from normal and reasonable practice inherent in the game, there will be no liability, as it cannot be avoided even when reasonable care is taken. Such incidents are regarded as mere accidents whose costs must be borne by the victim. The value of sports derives from their inherent conflict, speed, exertion, and physical contact. The occasional accident is the price to be paid by player or spectator for the benefits of sports.

Nonetheless, consent does not include participant's flagrant disregard for the rules or where the defendant intentionally injures or engages in reckless, willful, or wanton misconduct beyond the scope ordinarily understood for the activity, even though there is an inherent risk that this could occur (Duff, 1994; Drago 2002). In other words, those situations or conditions that are not inherent to an activity and not obvious or assessable by a plaintiff. For example, "poor instruction, defective equipment, lack of safety devices, faulty layout or construction, poor officiating, and dangerous environmental conditions the unexpected acts of other participants, improper conduct by co-participants, a lack of skill on the part of other participants, or an activity that has been conducted improperly. It will likely be found that the defendant did not fulfill his or her duty to the plaintiff and that the plaintiff did not assume the risk" (Hess 2002).

In summary, where negligence is found it is rare for a court to hold that the plaintiff waived any legal claim through a bargain to give up rights of action. Accordingly, more often than not, the common law defense of voluntary assumption of risk will rarely succeed. At the same time, where no negligence is found, or where injury arises from inherent risk, there is no need to consider voluntary assumption of risk as a special defense (Fast 2004).

\section{Conclusion}

In a non-sport situation, consent to an act that is unlawful in itself is irrelevant. Dueling, for example, is unlawful and the consent of the injured party is irrelevant to any subsequent legal proceedings. But in the area of sport, athletes with participate in sport activity assume and accept the inherent risk of that sport. In other words, participation in sport activity is assumed consent to the inherent risk and injury of sport.

Also there is a certain level of violent contact during sport and players are not necessarily negligent or grossly negligent for contact arising in the usual course of the game, thus there is authority suggesting that ordinary and reasonable violence that is incidental to the sport in question has the implied consent of participants, which means that athletes, particularly those participating in contact sports, assume the risk if due to another player's negligence. 
It seems, however, that a person cannot consent to the infliction of grievous bodily harm. So anger or hostility and a predominant intention to inflict substantial bodily harm may transform a sporting performance into a criminal activity. Therefore, the law has a role to play in visiting with penal sanctions some very serious instances of violence on the field of play. Moreover, if assumption of risk doctrine is to be imputed more readily, recreational facilities wouldn't be required to provide more information with regard to dangers associated with the sport in order for participants to be in a better position to weigh the risks, which participants would otherwise not have known the extent of, yet under the reforms, be held to have consented to in any event.

Therefore, the threat of prosecution and imposing civil and criminal liability will play a vital role in ensuring safe manners are maintained in sport and help prevent otherwise negligent acts.

It is in the public interest to reprimand such conduct as a means of deterrence.

But the courts will need to be cautious in how they apply criminal liability to the sporting industry so as not to diminish the essential nature of competitive sport.

\section{REFERENCES}

Aghainia, H. (2009). Fundamentals of Sport Law: Civil Liability In Sport [In Persian]. Tehran. DADGOSTAR Publisher.

Beloff, H., Kerr, T., Demetriou, M. (1999). Sports Law. Hart Publishing.

Bernardi, R. (2009). Leisure, Sport, and Assumption of Risk. Retrieved from www.bicyclelaw.com

Citron, J., Ableman, M. (2003). Civil Liability in the Arena of Professional Sports. Retrieved from www.goodmans.ca

Cotten, M., Cotton, D. (2002). Legal Aspects of Waivers in Sport, Recreation and Fitness Activities. PRC Publishing Inc.

Clarke, C. (2000). Law and Order on the Courts: Application of Criminal Liability for Intentional Fouls During Sporting Events. Law Journal, 1151.

Drago, A., (1995). Assumption of Risk in the Arena, on the Field and in the Mosh Pit: What Protection Does it Afford. Entertainment and Sports Lawyer, 13, 3-8.

Drago, A. (2002). Assumption of Risk: An Age-old Defense Still Viable in Sports \& Recreation Cases. Fordham Intellectual Property, Media \& Entertainment Law Journal, 3, 12(2), 582-608.

Duff, A. (1994). Civil Actions and Sporting Injuries Sustained by Professional Footballers. Scotts Law Times, 177.

Fast, K. (2004). Sport liability law a guide for amateur sports organizations and their insurers. Dolden Wallace Folick LLP.

Healey, D. (2005). Sport And The Law, $3^{\text {rd }}$ ed. University of New South Wales Press Ltd.

Hess, L. (2002). Sports And The Assumption of Risk Doctrine in New York. St. John's Law Review, 76, 457-781.

Jacobs, D. (2010). What is the Assumption of Risk Doctrine. Retrieved from Portland Personal Injury Law Blog.

Jonhnson, M., Easter, B. (2007). Legal Liability for Cheerleading Injuries: Implications for Universities and Coaches. Journal of Legal Aspect of Sport, 17, 213-252.

Keeton, W. P. Keeton, R. F. (1977). Torts: cases and materials. $2^{\text {nd }}$ ed. St. Paul: West Publishing Co.

Klar, L. (1996). Tort Law. $2^{\text {nd }}$ ed. Scarborough, Ont: Carswell.

Linden, A. (2001). Canadian Tort Law. $7^{\text {th }}$ ed. (pp. 42-43). Markham Ont.: Butterworths.

Mandell, J., Dozis, D. (2010). Primary Assumption of the Risk: Still Viable Defense, With Limitations. New York Law Journal, 244, 85.

Prosser, W., Wade, J. (1971). Cases and Materials on Torts. $5^{\text {th }}$ ed. West Law.

Saathi, B. (2008). Consent in criminal law. Retrieved from www.shvoong.com

Schot, N. (2005). Negligent liability in Sport. Sports Law eJournal, ePublications@ bond

Sparc. (2011). Liability of Sport and Recreation Organisations in New Zealand. Retrieved from www.sparc.org.nz

Spengler, J., Connaughton, A. (2003). A Quantitative Approach to Assessing Legal Outcomes in Reported Sport and Recreation Negligence Cases Involving Assumption of Risk. Entertainment Law, 2, 112-129.

Trupia, V. (2010). Lake George Central School District. Court of Appeals of New York. Retrieved from www.leagae.com. 
Uberstine, A. (1997). Law of Professional and Amateur Sports. Retrieved from http://law.widener.edu/lawlibrary.aspx Wong, G. (2010). Essential of Sports Law. $4^{\text {th }}$ ed. Westport, Connecticut: ABC-CLIO Publishers.

Woska, W. (1991). Negligent Employment Practices. Labor Law Journal, 16, 602-610.

Yeo, S., (2001). Accepted Inherent Risks Among Sporting Participants. Tort Law Review, 118 \& 128.

AUTHOR'S ADDRESS: $\quad$ Azadeh Mohamadinejad

Semmelweis University

Faculty of Sport and Physical Education Sciences (TF)

1123 Alkotás u. 44.

Budapest, Hungary

Email: Azadehmohamadinejad@gmail.com 